\title{
Psychodynamic Theory
}

\author{
Kathleen Holtz Deal
}

\begin{abstract}
Psychodynamic theory, a theory of personality originated by Sigmund Freud, has a long and complex history within social work and continues to be utilized by social workers. This article traces the theory's development and explains key concepts with an emphasis on its current relational focus within object relations theory and self-psychology. Empirical support for theoretical concepts and the effectiveness of psychodynamic therapies is reviewed and critiqued. Future directions are discussed, including addressing cultural considerations, increasing research, and emphasizing a relational paradigm
\end{abstract}

Keywords: Psychodynamic theory; empirical support; social work practice

\section{HISTORICAL DEVELOPMENTS}

Psychodynamic theory, a theory of personality originated by Sigmund Freud, has a long and complex history within social work. The young profession's desire for a scientific base, Mary Richmond's choice of a medical model to assess and treat client problems, and the wide impact of Freud's ideas on the popular culture, contributed to the prominent role of psychodynamic thought in the theory base of social work (Germain, 1970; Greene \& Ephross, 1991). In addition, the movement of large numbers of social workers into areas of practice heavily influenced by psychiatrists, including child guidance and work with war veterans and their families, exposed them to psychodynamic ideas (Brandell, 2004; Goldstein, 1995). The diagnostic or psychosocial school developed by such early contributors as Mary Richmond, Charlotte Towle, Gordon Hamilton, and Florence Hollis, used psychodynamic concepts to help explain complex human behaviors. These writers attempted to integrate concepts, such as the role of drives in human motivation, stages of psychosexual development, and ego defense mechanisms into a person-and-environment framework to explain the interaction of interpersonal and societal factors. These efforts resulted in social work widely utilizing psychodynamic concepts, while retaining the profession's own identity and psychosocial focus (Orcutt, 1990).

When psychoanalysts such as Hartmann, Erikson, and White theorized a more autonomous role for the ego, social work adopted this theoretical shift as consistent

Kathleen Holtz Deal, Ph.D. is associate professor at The University of Maryland, School of Social Work, Baltimore, MD, 21201-1777. 
with the profession's perspective that individuals actively interact with their environment and are capable of growth and change throughout their life times (Greene \& Ephross, 1991). Perlman's development of the popular problem-solving model is heavily based on ego psychology (Brandell, 2004; Goldstein, 1995).

During the 1960s and 1970s, psychodynamic theories fell out of favor. Psychodynamic principles that explained human behavior were criticized as overly deterministic, resulting in "blaming the victim" (Goldstein, 1995). Their focus on intrapsychic phenomenon was seen as inadequate to explain the massive social problems of the day, including poverty, racism, sexism, and heterosexism. During this same period, alternative ways to understand individual and family behaviors arose, including behavioral, cognitive, existential, and family systems theories, greatly expanding the profession's theoretical base.

These expansions offer many theoretical options to social workers; however, psychodynamic theories continue to be included in HBSE textbooks utilized by social work practitioners (Saltman \& Greene, 1993) and provide the theoretical base for such journals as the Clinical Social Work Journal and Psychoanalytic Social Work. The NASW Standards for Clinical Social Work in Social Work Practice (National Association of Social Workers, 2005) include psychodynamic theory in a list of theories on which clinical social workers base their practice. The persistence of psychodynamic theory within social work can be partially understood by changes within the theory itself, particularly the theory's shift to a relational focus, which resonates with social work's traditional emphasis on the importance of interpersonal relationships.

\section{KEY THEORETICAL CONCEPTS AND PRINCIPLES}

Psychodynamic theory attempts to explain human behavior in terms of intrapsychic processes and the repetition of interpersonal patterns that are often outside of an individual's conscious awareness and have their origins in childhood experiences. Its long history reflects frequent modifications and differences among major theorists around key concepts and principles. Given psychodynamic theory's complex evolutionary history, this section is organized around the theory's four major schools of thought, commonly conceptualized as drive theory, ego psychology, object relations theory, and self-psychology (Greenberg \& Mitchell, 1983; Mishne, 1993).

\section{Drive Theory}

Psychodynamic theory began with Sigmund Freud's belief that drives, biologically-based impulses that seek gratification, play a critical role in determining human behavior. Freud originally hypothesized sex (eros) and self-preservation as the primary drives, later modifying his ideas to include a destructive or aggressive drive (Greenberg \& Mitchell, 1983). The term sexual is understood broadly to include pleasure across the body's erogenous zones. In psychodynamic theory, the zone of bodily pleasure shifts during the normal stages of psychosexual development (oral, anal, phallic, and genital). Early libidinal stages arise "in connection with important nonsexual bodily functions, such as sucking (when feeding) or anus arousal (when defecating)" (Mishne, 1993, p. 11). The phallic stage is particularly 
critical in personality development, because, during this period, the developing child experiences and ideally resolves the Oedipus conflict, resulting in a mature, integrated identity (Brandell, 2004). During the Oedipus conflict, the child typically desires the opposite-sex parent, while wishing to eliminate the same-sexed parent, who is viewed as a rival. In resolving this conflict, the child fears retaliation for his or her wishes, relinquishes the desire for an exclusive love relationship with the opposite-sex parent, and identifies with the same-sex parent. Family members other than parents, such as siblings, can become objects of desire, depending on family dynamics and configurations (Brandell, 2004).

In seeking gratification of their endogenous drives, individuals are confronted with the frustrations imposed by the external world (i.e., parents, society), which frequently oppose such gratification. Freud (1946) viewed the conflict between the drives and the restraining forces that forbid, delay, or limit drive gratification as a necessary condition for the development of civilization. However, restraints on drive gratification are not only externally imposed on individuals, but they eventually come from within the individual, through the development of the psychic structures of the ego and superego. Freud conceptualized the ego as developing from the id, the seat of the drives, in reaction to the frustrations of the external world (Greenberg \& Mitchell, 1983). The ego performs functions that help the individual effectively adapt to reality, including the ability to accurately perceive the world, respond to both external and internal stimuli, and control the drives (Mishne, 1993). The superego is a structure formed initially by the child's internalization of parental ideals and prohibitions, which become transformed into abstract principles after the Oedipal period (Milrod, 2002). The superego has four functions: providing direction (based on the ego-ideal), limiting behavior, punishing unacceptable behavior, and observing and measuring the ego against the ego ideal (Milrod). Because the superego also contains early punitive tendencies, it can be harsh, intolerant, and demanding, if development does not proceed well (Schamess, 2002).

When an individual's unacceptable drive-based wishes and fantasies threaten to become conscious, they trigger conflicts between the drives (residing in the unconscious id) and the superego and/or the ego. If the individual successfully represses these wishes, they return to the unconscious. If repression is unsuccessful, the individual experiences anxiety, activating the ego's defenses, defined as "psychological activities that reduce the unpleasure of psychic conflict by blocking, inhibiting, or distorting awareness of disturbing mental contents" (Brandell, 2004, p. 36). There may be a disguised breakthrough of the unacceptable impulse, which manifests itself as a symptom or compromise formation that both partially conceals and indirectly expresses the underlying conflict (Mishne, 1983). For example, Joe's boss gives him a poor performance evaluation. Joe reacts by assuring himself and his wife that, although he is disappointed, his boss is only doing his job and has Joe's best interests at heart (the defense of intellectualization). Joe represses his unconscious wish to retaliate and injure his boss, which triggers an intrapsychic conflict between his id and his ego, which can understand and evaluate the negative repercussions of such an action and/or his superego, which views harming another person as wrong. Subsequently, when Joe is around his 
boss, he begins to experience prolonged coughing spells, which he feels unable to stop. Joe's symptom of loud, uncontrolled coughing is a compromise formation, because it partially conceals his wish to injure his boss (when he's coughing, he feels vulnerable, rather than aggressive; he's unable to physically attack or even speak to his boss), while allowing Joe to indirectly express it (Joe's loud coughing itself is aggressive, in that coughing makes it impossible to hear his boss and it could spread germs to his boss, making him ill).

\section{Ego Psychology}

Sigmund Freud's (1923/1961) structural theory conceptualized the ego as relatively weak in relation to the id. Building on his work, later theorists expanded the role of the ego beyond drive regulation to include organizational and synthetic functions, including judgment, reality testing, thought processes, regulating internal and external stimuli, regulating self-esteem, and organizing the conflicting aspects of the personality (Goldstein, 1995; Schamess, 2002).

In contrast to Freud's idea that the ego developed solely from the id, Hartmann (1939) theorized that some aspects of ego functioning, such as perception, memory, intellectual ability, language ability, and motor activity develop autonomously, that is, they are free of intrapsychic conflict. White (1963) posited that individuals have a drive for mastery equal to the drives of sex and aggression, such that human beings derive satisfaction by exploring and manipulating their environment. He described this drive for competence or "effectance," as implying "a primary positive interest in the world apart from its drive-reducing properties" ( $p$. 47). Through these modifications to psychodynamic theory, ego psychology changed the focus of inquiry from how pathology develops to how individuals grow, adapt, and master their environments (Greenberg \& Mitchell, 1983; Goldstein, 1995). This shift moved psychodynamic theory from a primary focus on intrapsychic phenomenon to include the significance of reality or the environment in individual development.

This shift can be seen in the work of Erikson (1959), who expanded Freud's earlier psychosexual stages by developing eight psychosocial stages that broaden the process of personality development to include the impact of social and cultural influences. By describing the stages from birth to old age, Erikson emphasized the ongoing development of the individual across the entire life cycle, with each stage presenting unique tasks and opportunities for further identity development and refinement.

\section{Object Relations}

Greenberg and Mitchell (1983) describe a major shift in psychodynamic theory, from the use of drives and their derivatives to explain human behavior (drive/structure model), to understanding individuals as "object seeking," that is, motivated to connect with others (relational/structure model). Consistent with this focus, object relations theory has a particular interest in pre-Oedipal relationships, including the nature of the attachment between infants and their caregivers and the process of separation-individuation. Object relations theory posits that, through repeated interactions, children internalize representations of themselves and their caregivers. The term object relations, therefore, "refers not only to 'real' 
relationships with others, but also to the internal mental representations of others and to internal images of self as well" (Flanagan, 2002, p. 128). These internalized representations of self and others begin as cognitive constructions based on experiences, ideas, and memories, but they take on emotional meaning, becoming cognitive-affective templates for future relationships (Flanagan). Because many factors can affect the internalization process, including the child's early experiences, drives, needs, and perceptions, internal representations may not correspond to the objective characteristics of the self or the other person (Fonagy \& Target, 1996; Goldstein, 1995; Greenberg \& Mitchell, 1983).

The following example illustrates how self and other representations are formed, become internalized, and affect future relationships. Through repeated interactions with a responsive caregiver who generally provides good care, an infant is able to internalize a sense of herself as safe and is able to affect her environment. For example, when she is hungry and cries, she is comforted and fed. Through these repeated interactions, she also internalizes the caring and dependable "other" who is connected to her experience of herself. Based on these internalized representations, the child will be able to enter future relationships, trusting that she is competent with interacting with her environment and that others can be depended upon. Because representations of both the self and the other are internalized, both representations contribute to the formation of the self; therefore, this child is able to trust others (self-representation) and be dependable herself (other representation).

Object relations theory is not a unified theory, and major theorists differ on important major concepts and principles, such as the extent to which drives continue to play a role in motivating human behavior, the process through which internalization of objects occurs, and the importance of "real" relationships versus internalized representations (Brandell, 2004; Greenberg \& Mitchell, 1983; Goldstein, 1995). Key concepts developed by Winnicott (1965), a member of the British school of object relations, are included in this section, because of his influence on social work from clinical practice (Applegate \& Bonovitz, 1995; Chescheir \& Schulz, 1989; Seinfeld, 1993) to case management (Kanter, 1990). Winnicott's collaboration with his wife, Clare Britton Winnicott, a social worker, was one of mutual influence (Kanter, 1990).

Winnicott (1965) described the holding environment as the physical and emotional environment offered by the infant's caregiver, which serves to support the needs and wants of the developing infant. A good enough mother is one who can meet the child's needs by responding appropriately to the infant's spontaneous gestures or biologically-based aliveness, both which represent the infant's core potential. If these environmental conditions are met, the child's true self, a sense of being alive, creative, and genuine, is able to flourish. If the mother or caregiver consistently neglects the infant's needs or impinges by substituting her own needs for those of the child, the child learns to ignore her or his own authentic needs, resulting in a false self, which shields the true self and is "prematurely and compulsively attuned to the claims and requests of others" (Greenberg \& Mitchell, 1983, p. 194). Gradual, small failures in responsiveness by the mother, however, help the infant's ego develop through experiencing the world separate from the 
mother, thus facilitating the separation-individuation process (Brandell, 2004; Greenberg \& Mitchell, 1983).

\section{Self-Psychology}

In contrast to Freud's vision of human beings beset by intrapsychic conflict between their drives and the constraints of the ego and superego, Kohut developed a deficit theory in which humans are seen as isolated, fragmented, and vulnerable (Brandell, 2004). Kohut wrote, primarily from the 1960s through the 1980s, a cultural period marked by an exaggerated emphasis on self-fulfillment. He encountered patients whom he viewed as having a fragile, fragmented sense of self and who were "extremely sensitive to failures, disappointments, and slights" (Kohut \& Wolf, 1978, p. 413). Kohut connected such deficits in these narcissistic individuals to their parents' lack of empathic responsiveness.

He explained that parents first serve as self-objects "in which the object is actually experienced as an extension of the self, without psychological differentiation" (Brandell, 2004, p. 63). Individuals need three types of self-object experiences to facilitate the development of a complete tripolar self. They need mirroring selfobjects who will praise and admire their unique capacities and characteristics to provide a sense of healthy grandiosity and self-confidence, self-objects who can be idealized (called the parent imago) as persons with whom the child can merge in order to feel safe and complete, and partnering self-objects to provide an experience of twinship, or being like others (Brandell, 2004; Flanagan, 2002). Through the process of transmuting internalization, individuals gradually take in the functions initially performed by self-objects, so that these functions become part of the child's self-structure (Brandell, 2004). Although the internalization process described by Kohut is similar to how the "other" is internalized in object-relations theory, self-psychology emphasizes that empathic attunement is the key environmental condition facilitating the development of a healthy, cohesive, and secure self. Another difference is that Kohut believed that individuals continue to need self-objects throughout their lives, a contrast to the separation-individuation process described by object-relations theorists.

\section{GOALS AND OUTCOMES}

Psychodynamic theory seeks to explain human behavior largely through understanding unconscious processes, that is, forces that lie outside of an individual's awareness. Referred to as depth psychology, psychodynamic thought attempts to explain phenomena that, on the surface, may appear unrelated or to serve no obvious purpose. The theory is considered deterministic in that early intrapsychic and interpersonal experiences shape personality and determine later-life choices. This theory's primary emphasis is on individual behavior, although it is also used to explain dyadic relationships, particularly the parent-child dyad and small groups.

While criticized as focusing on pathology, rather than on individuals' strengths and capabilities (Robbins, Chatterjee, \& Canda, 2006), contemporary trends in psychodynamic theory, such as ego psychology, include an emphasis on ego mastery, competence, and normal development across the life cycle (Brandell, 2004). 
Object-relations theory seeks to explain how an individual's external environment gets "taken in" and shapes the individual's growth and development as well as how what is "inside" effects how the individual shapes her or his external world (Flanagan, 2002). Therefore, the individual's interaction with his or her surrounding environment is critical to development.

Treatment modalities based on psychodynamic theory exist along a continuum, from those intended to modify or change personality structures, to those that aim to support, enhance, and strengthen the individual's functioning. Egosupportive approaches focus on the present situation and conscious processes to improve adaptive coping abilities, while ego-modifying approaches focus on the use of insight to understand preconscious and/or unconscious conflicts and their effects on behavior with the goal of modifying/reorganizing personality (Goldstein, 1995).

\section{EMPIRICAL SUPPORT}

Empirical support for psychodynamic theory can be divided into two related, and sometimes overlapping, areas: studies that test the effectiveness of psychodynamic treatment and those that support the validity of key theoretical concepts. Empirical support for treatments based on psychodynamic theory suffers from numerous limitations. There is a paucity of well-designed studies; interventions identified as "psychodynamic" are frequently poorly defined, and standardized outcome measures are difficult to develop when the treatment focus is broader than symptom relief (Fonagy, Roth, \& Higgitt, 2005; Lis, Zennaro, \& Mazzeschi, 2001; Messer \& Warren, 1995).

A review of evidence-based practices for social workers by O'Hare (2005) yielded little support for the effectiveness of psychodynamic treatments. Bloom, Yeager, and Roberts (2006a) cite some support for brief psychodynamic treatment for depression in the elderly (Niedereche as cited in Bloom et al., 2006a) and chronic anxiety (Crits-Christoph as cited in Bloom et al., 2006b), while concluding that brief cognitive behavioral treatments have generally been found to be more efficacious than brief psychodynamic treatments. By contrast, a recent social work study of psychiatric outpatients treated with psychodynamic psychotherapy, which used a psychodynamic outcome measure, found significant improvements in symptom distress, interpersonal relationships, and social-role functioning over the course of a year (Roseborough, 2006).

Research reviews from related disciplines report greater, albeit limited, support for the effectiveness of psychodynamic treatment models. In an extensive review of psychodynamic treatments for adult mental disorders, Fonagy et al. (2005) concluded that empirical studies provide limited support for the efficacy of shortterm psychodynamic psychotherapy (an average of 20 sessions) for some disorders: major depression (comparable to cognitive-behavioral therapy or problemsolving therapy in random controlled trials), anorexia nervosa (as effective as intensive behavioral and strategic family therapy), opiate abuse (one trial; better results at follow-up than cognitive behavioral therapy and drug counseling), posttraumatic stress disorder (despite methodological problems with the trials), and borderline personality disorder (models that offer a structured framework). This 
same review concludes that long-term psychodynamic treatment appears to be consistently helpful for individuals with neurotic disorders.

A meta-analysis of 11 studies of brief psychodynamic therapy conducted by CritsChristoph (as cited in Messer \& Warren, 1995), which used rigorous selection criteria, found that psychodynamic treatment produced outcomes much better than waiting-list controls, slightly better than non-psychiatric treatments (e.g., self-help groups), and equal to alternative psychotherapies and medication. Leichsenring and Leibing's (2003) meta-analysis of 25 studies of psychodynamic and/or cognitive treatment of personality disorders found both approaches to be effective in improving personality disorder pathology.

Despite the wide use of psychodynamic treatments for children and adolescents, few sound empirical studies of their effectiveness have been conducted (Fonagy, Target, Cottrell, Phillips, \& Kurtz, 2002; Lis et al., 2001). One comprehensive study involved a retrospective chart review of more than 700 children and adolescents treated with either psychoanalysis (4-5 times per week) or psychodynamic psychotherapy (1-3 times per week) at the Anna Freud Centre (Fonagy \& Target, 1996). For those patients who continued in treatment for a minimum of six months, $56 \%$ of those in psychoanalysis and $44 \%$ of those in psychodynamic psychotherapy, moved from the clinical to the normal range on the Hampstead Child Adaptation Measure (HCAM). This research found the following variables to be associated with greater treatment effectiveness: longer treatment, age (children under age six showed the greatest improvement), treatment intensity (children did better in psychoanalysis, particularly seriously disturbed children; adolescents with less intensive treatment), and the presence of an anxiety disorder (either alone or combined with a disruptive disorder). Children who showed relatively poor outcomes included those with mental retardation, pervasive developmental disorders, serious disruptive disorders, and depressive disorders.

Empirical studies show some support for several psychodynamic concepts. Defense mechanisms are one area of considerable theoretical and empirical inquiry (Conte \& Plutchik, 1995). Consistent with the hypothesized relationship of defenses to overall ego functioning, Vaillant's (1993) longitudinal study found that the use of mature ego defenses was associated with better mental health, psychosocial adjustment, and life satisfaction, independent of gender, social class, and education. On the other hand, Johnson's (1991) critique of studies related to the psychodynamic concepts of unconscious processes, defense mechanisms, and developmental stages, concludes that empirical evidence for these concepts is weak and/or flawed. The concept of the therapeutic alliance, defined as "the observable ability of the therapist and patient to work together in a realistic collaborative relationship based on mutual respect, liking, trust, and commitment to the work of treatment" (Foreman \& Marmar, 1985, p. 922) was first developed within psychodynamic theory (Greenson, 1967). Now widely accepted across theories and measured empirically, the therapeutic alliance has been found to exert a small but consistent influence on successful client outcome (Crits-Christoph \& Gibbons, 2003; Roth \& Fonagy, 2005).

Psychodynamic theory posits that individuals repeat relationship patterns internalized in childhood in their current relationships, including their relationship with their therapist (transference). The development and testing of the Core 
Conflictual Relationship Theme method (CCRT) by Luborsky and his colleagues (Barber \& Crits-Christoph; Fried, Crit-Christoph \& Luborsky, both as cited in Charman, 2003) offers support for the validity of these repetitious interactive patterns.

Recent research within neurobiology explains how infants' repeated experiences with early caregivers shape structural connections within the brain. This research offers neurobiological support for such object relations and self-psychology concepts as internalized object relations, mirroring, and affect regulation as occurring through repeated interpersonal processes (Applegate \& Shapiro, 2005; Schore, 1997). For example, Schore describes how interdisciplinary developmental research provides information on the mechanisms through which the orbitofrontal cortex of the infant's developing brain integrates information from the emotions on the caregiver's face with changes in the infant's self-state to generate internalized object-relations consisting of self and other representations linked by affect.

\section{FUTURE DIRECTIONS: IMPLICATIONS FOR SOCIAL WORK}

Current trends in psychodynamic theory include a vibrant interest in theory development, including cultural considerations, an emphasis on a relational paradigm, and increasing support for research, all of which have implications for social work. Object relations theory and self-psychology helped move psychodynamic theory from a one-person psychology focused on the intrapsychic dynamics of an individual to a two-person psychology, focused on relationships between individuals, including the client and clinician. Social work has a long history of emphasizing the importance of interpersonal relationships, including the client-worker relationship, in understanding how individuals develop and change (Biestek, 1957; Coady, 1993; Sudbery, 2002). In fact, Horowitz (1998) views psychodynamic theory's relational paradigm as reflecting much of this decades long-tradition within social work, albeit without direct recognition of social work's contributions. Given the consistency of a relational emphasis in both social work practice and current psychodynamic theory, social workers are well-positioned to continue contributing to theory development in this area, particularly around the nature and importance of the client-worker relationship.

Psychodynamic theory has long been criticized for failing to adequately address the cultural context of human development (Robbins et al., 2006). Although this criticism still has some validity, there are increased efforts to address this gap. Social workers, such as Mattei (2002), use psychodynamic theory to explain such phenomena as racial dynamics and the symbolic significance of color and to explore cultural differences in identity development and the nature of boundaries between self and other. Many social workers address the application of psychodynamic theory to clinical work with diverse populations (see, for example, PerezFoster, Moskowitz, \& Javier, 1996). The richness of theory development around the concept of intersubjectivity (Atwood \& Stolorow, 1984), that is the mutual influence of client and clinician on each other, focuses on the contributions of both persons to the therapeutic process. This approach lends itself to examining the effects of such variables as culture and race within psychodynamic treatment. 
Studies of community treatment settings suggest that many clients suffer from co-morbid disorders, rather than the single diagnosis desired for randomized controlled trials (Westen, Morrison, \& Thompson-Brenner, 2004). Such clients, including those with multiple psychosocial problems and those mandated to receive services, are frequently encountered by clinical social workers. Psychodynamic theory offers a well-developed conceptual framework for understanding what may appear to be unrelated symptoms or the repetition of seemingly unrewarding intrapsychic and interpersonal patterns, suggesting its potential to address the complex, multiple problems of many clients served by social workers. A mutually informative process of research and theory development could add greatly to understanding these clients, who are frequently left out of treatment-effectiveness studies. Such research should include determining which clients do better with ego-supportive versus insight-oriented psychodynamic treatment. For example, low-functioning clients do poorly when therapists make interpretations, suggesting that a minimal level of interpersonal maturity and stability may be needed for insight-oriented treatment to be therapeutic (Roth \& Fonagy, 2005).

Case studies, the primary type of psychodynamic therapy research conducted in the past, have their strengths and weaknesses (Aveline, 2005). Current research on treatment effectiveness is much more diverse and includes quantitative and qualitative studies, despite the challenges in operationalizing psychodynamic concepts. For example, some researchers examine therapeutic processes, such as interactional patterns and the therapeutic alliance, rather than outcomes, as particularly suited to the nature of psychodynamic treatment (Charman, 2003; Lees, 2005). Others suggest using a social constructivist research paradigm to study psychodynamic treatment. In this post-modern view, the goal of psychodynamic treatment is to understand truth as a narrative co-constructed by client and clinician, rather than an objective reality (Lees, 2005).

\section{References}

Applegate, J.S., \& Bonovitz, J.M. (1995). The facilitating partnership: A Winnicottian approach for social workers and other helping professionals. Northvale, NJ: Jason Aronson.

Applegate, J.S., \& Shapiro, J.R. (2005). Neurobiology for clinical social work: Theory and practice. New York: Norton.

Atwood, G., \& Stolorow, R. (1984). Structures of subjectivity: Explorations in psychoanalytic phenomenology. Hilldale, NJ: Analytic.

Aveline, M. (2005). Clinical case studies: Their place in evidence-based practice. Psychodynamic Practice, 11(2), 133-152.

Biestek, F.B. (1957). The casework relationship. Chicago: Loyola University.

Bloom, B.L., Yeager, K.R., \& Roberts, A.R. (2006a). The implications of controlled outcome studies on planned short-term psychotherapy with depressive disorders. In A.R. Roberts \& K.R. Yeager (Eds.) Foundations of evidence-based social work practice (pp. 258-274) New York: Oxford University Press.

Bloom, B.L., Yeager, K.R., \& Roberts, A.R. (2006b). Evidence-based practice with anxiety disorders: Guidelines based on outcome studies. In A.R. Roberts \& K.R. Yeager (Eds.) Foundations of evidence-based social work practice (pp. 275-290). New York: Oxford University Press.

Brandell, J.R. (2004). Psychodynamic social work. New York: Columbia University Press. 
Charman, D. (2003). Paradigms in current psychotherapy research: A critique and the case for evidencebased psychodynamic psychotherapy research. Australian Psychologist, 38(1), 39-45.

Chescheir, M.W., \& Schulz, K.M. (1989). The development of a capacity for concern in antisocial children: Winnicott's concept of human relatedness. Clinical Social Work Journal, 17(1), 24-39.

Coady, N. (1993). The worker-client relationship revisited. Families in Society, 74(5), 291-298.

Conte, H.R., \& Plutchik, R. (Eds.). (1995). Ego defenses: Theory and measurement. New York: John Wiley.

Crits-Christoph, P., \& Gibbons, M.B.C. (2003). Research developments on the therapeutic alliance in psychodynamic psychotherapy. Psychoanalytic Inquiry, 23(2), 332-349.

Erikson, E.H. (1959). Identity and the life cycle. New York: Norton.

Flanagan, L.M. (2002). Object relations theory. In J. Berzoff, L.M. Flanagan \& P. Hertz (Eds.), Inside out and outside in (pp. 127-171). Lanham, MD: Jason Aronson.

Fonagy, P., Roth, A., \& Higgitt, A. (2005). Psychodynamic psychotherapies: Evidence-based practice and clinical wisdom. Bulletin of the Menninger Clinic, 69(1), 1-58.

Fonagy, P., \& Target, M. (1996). Predictors of outcome in child psychoanalysis: A retrospective study of 763 cases at the Anna Freud Centre. Journal of the American Psychoanalytic Association, 44, 27-77.

Fonagy, P., Target, M., Cottrell, D., Phillips, J., \& Kurtz, Z. (2002). What works for whom? A critical review of treatments for children and adolescents. New York: The Guilford Press.

Foreman, S.A., \& Marmar, C.R. (1985). Therapist actions that address initially poor therapeutic alliances in psychotherapy. American Journal of Psychiatry, 142(8), 922-926.

Freud, S. (1961). The ego and the id. In J. Strachey (Ed. \& Trans.), The standard edition of the complete psychological works of Sigmund Freud (Vol. 19, pp. 3-66). London: Hogarth Press. (Original work published 1923).

Freud, S. (1946). Civilization and its discontents ( $3^{\text {rd }}$ ed.). London: Hogarth Press.

Germain, C. (1970). Casework and science: A historical encounter. In R.W. Roberts \& R.H. Nee (Eds.), Theories of social casework (pp. 3-32). Chicago: University of Chicago Press.

Goldstein, E.G. (1995). Ego psychology and social work practice (2 ${ }^{\text {nd }}$ ed.). New York: The Free Press

Greenberg, J.R., \& Mitchell, S.A. (1983). Object relations in psychoanalytic theory. Cambridge, MA: Harvard University Press.

Greene, R.R., \& Ephross, P.H. (1991). Classic psychoanalytic thought, contemporary developments, and clinical social work. In R.R. Green \& P.H. Ephross (Eds.), Human behavior theory and social work practice (pp. 39-78). New York: Aldine de Gruyter.

Greenson, R.R. (1967). The technique and practice of psychoanalysis (vol. 1). New York: International Universities Press.

Hartmann, H. (1939). Ego psychology and the problem of adaptation. New York: International Universities Press.

Horowitz, J. (1998). Contemporary psychoanalysis and social work theory. Clinical Social Work Journal, 26(4), 369-383.

Johnson, H.C. (1991). Theories of Kernberg and Kohut: Issues of scientific validation. Social Service Review, 65(2), 403-433.

Kanter, J. (1990). Community-based management of psychotic clients: The contributions of D.W. and Clare Winnicott. Clinical Social Work Journal, 18(1), 23- 41

Kohut, H., \&Wolf, E.S. (1978). The disorders of the self and their treatment: An outline. International Journal of Psychoanalysis, 59, 413-425.

Lees, J. (2005). A history of psychoanalytic research. Psychodynamic Practice, 11(2), 117-131.

Leichsenring, F., \& Leibing, E. (2003). The effectiveness of psychodynamic therapy and cognitive behavior therapy in the treatment of personality disorders: A meta-analysis. American Journal of Psychiatry, 160(7), $1223-1232$.

Lis, A., Zennaro, A., \& Mazzeschi, C. (2001). Child and adolescent empirical psychotherapy research. European Psychologist, 6(1), 36-64. 
Mattei, L. (2002). Coloring development: Race and culture in psychodynamic theories. In J. Berzoff, L.M. Flanagan \& P. Hertz (Eds.), Inside out and outside in (pp. 221-245). Lanham, MD: Jason Aronson.

Messer, S.B., \& Warren, C.S. (1995). Models of psychodynamic brief therapy: A comparative approach. New York: Guilford Press.

Milrod, D. (2002). The superego: Its formation, structure, and functioning. The Psychoanalytic Study of the Child, 57, 131-148.

Mishne, J.M. (1993). The evolution and application of clinical theory: Perspectives from four psychologies. New York: The Free Press.

National Association of Social Workers. (2005). NASW standards for clinical social work in social work practice. Washington, D.C.: Author.

O'Hare, T. (2005). Evidence-based practices for social workers: An interdisciplinary approach. Chicago: Lyceum Books.

Orcutt, B.A. (1990). Science and inquiry in social work practice. New York: Columbia University Press.

Perez-Foster, R., Moskowitz, M., \& Javier, R. (Eds.). (1996). Reaching across boundaries of cultures and class: Widening the scope of psychotherapy. Lanham, MD: Jason Aronson.

Robbins, S.P., Chatterjee, P., \& Canda, E.R. (2006). Contemporary human behavior theory ( $2^{\text {nd }}$ ed.). Boston: Allyn \& Bacon.

Roseborough, D.J. (2006). Psychodynamic psychotherapy: An effectiveness study. Research on Social Work Practice, 16(2), 166-175.

Roth, A., \& Fonagy, P. (2005). What works for whom? A critical review of psychotherapy research. New York: The Guilford Press.

Saltman, J.E., \& Greene, R. (1993). Social workers' perceived knowledge and use of human behavior theory. Journal of Social Work Education, 29(1), 88-98.

Schamess, G. (2002). Ego psychology. In J. Berzoff, L.M. Flanagan, \& P. Hertz (Eds.), Inside out and outside in (pp. 67-101). Lanham, MD: Jason Aronson.

Schore, A.N. (1997). Interdisciplinary developmental research as a source of clinical models. In $\mathrm{M}$ Moskowitz, C. Monk, C. Kaye \& S. Ellman (Eds.), The neurobiological and developmental basis for psychotherapeutic intervention (pp. 1-71). Northvale, NJ: Jason Aronson.

Seinfeld, J. (1993). Interpreting and holding: The maternal and paternal functions of the psychotherapist. Northvale, NJ: Jason Aronson Inc.

Sudbery, J. (2002). Key features of therapeutic social work: The use of relationship. Journal of Social Work Practice, 16(2), 149-162.

Vaillant, G.E. (1993). The wisdom of the ego. Cambridge, MA: Harvard University Press.

Westen, D., Morrison, K., \& Thompson-Brenner, H. (2004). The empirical status of empirically supported psychotherapies: Assumptions, findings, and reporting in controlled clinical trials. Psychological Bulletin, 130, 631-663.

White, R.W. (1963). Ego and reality in psychoanalytic theory: A proposal regarding independent ego energies. Psychological Issues. Monograph No 11., New York: International Universities Press.

Winnicott, D.W. (1965). The maturational processes and the facilitating environment. New York: International Universities Press, Inc.

\section{Author's Note:}

Address correspondence to: Kathleen Holtz Deal, Ph.D., associate professor, University of Maryland, School of Social Work, 525 West Redwood Street, Baltimore, MD 21201-1777, USA. e-mail: kdeal@ssw.umaryland.edu. 